\title{
Reflecting on the Global Report on Adult Learning and Education in the "Post-Truth Society"
}

Adult Education Quarterly

2017, Vol. 67(3) 228-237

(C) The Author(s) 2017

Reprints and permissions: sagepub.com/journalsPermissions.nav DOI: $10.1177 / 0741713617700675$ journals.sagepub.com/home/aeq

@SAGE

\section{Shirley Walters' and Kathy Watters'}

\begin{abstract}
This article contextualizes and reviews the third global report on adult learning and education (ALE) released by UNESCO in 2016. The authors suggest that it is a visionary document, which is articulated through the bringing together of data from a range of areas that are usually kept apart. They recognize the report as a bold attempt to project what role ALE plays, or could play, within a holistic philosophy and approach to lifelong learning. They argue that given the ambitious nature of the task, and the inevitable tensions and contradictions that exist within a report of this nature, the report both fails to present a robust picture of ALE and succeeds as an advocacy document toward achievement of the Sustainable Development Goals. They recognize that the political and pedagogical work undertaken by the third Global Report on Adult Learning and Education is at an early stage. Alongside this work, they argue for the importance of the broader nonformal and informal ALE, including popular education, as a means of challenging the "post-truth society."
\end{abstract}

\section{Keywords}

GRALE III, adult learning and education, popular education, post-truth society

\section{Introduction}

The United Nations Educational, Scientific and Cultural Organization's (UNESCO) third Global Report on Adult Learning and Education (GRALE III) report was

\footnotetext{
'University of Western Cape, Cape Town, South Africa

\section{Corresponding Author:}

Shirley Walters, Professor Emerita, University of Western Cape, 22 Rhodes Drive, Bishops Court, Cape Town 7708, South Africa.

Email: ferris@iafrica.com
} 
launched at meetings hosted by the International Council for Adult Education in Latin America, Asia, Europe, and Africa, during 2016. Shirley attended the meeting in Ougoudougou, Burkina Faso. Present were about 50 adult educators, mainly from West Africa, who were listening intently to a presentation by Werner Mauch from the UNESCO Institute for Lifelong Learning (UIL). During the discussion, it became apparent that the data presented did not necessarily reflect the experiences of the people in the room. This led to a rich engagement with the report. In this article, we situate the timely GRALE III report within contemporary global contexts, describe the processes and the outcomes of research, and discuss the inevitable tensions and contradictions that exist within a report of this nature.

\section{Context}

Questions about the roles and effectiveness of adult learning and education (ALE) are being raised sharply particularly in light of the political developments in both the United Kingdom with the BREXIT vote to exit the European Union and the United States with the U.S. presidential election. The Oxford Dictionary in November 2016 chose post-truth as its word of the year, defining the adjective as "relating to or denoting circumstances in which objective facts are less influential in shaping public opinion than appeals to emotion and personal belief" (Harris, 2016). The willful spreading of misinformation, deceit, or ignorance is, of course, not new. In the 1970s, Robert Proctor, a science historian from Stanford University, studied the practices of tobacco firms and how they had spread confusion about whether smoking caused cancer. He created a word for the study of deliberate propagation of ignorance: agnotology. There are many contemporary examples in addition to BREXIT and the U.S. elections, for example, among AIDS or climate change denialists. David Dunning warns that the Internet is helping propagate ignorance as it is a place where everyone has a chance to be their own expert, "which makes them prey for powerful interests wishing to deliberately spread ignorance" (Kenyon, 2016). In a related comment, Alan Tuckett, former director of the then-influential U.K.-based National Institute for Adult and Continuing Education, stated in conversation, "The rise of populist authoritarianism is a direct threat to adult learning."

These developments are at a time when GRALE III reports on "powerful data and practical examples showing that adult learning and education help individuals become and stay healthier, improve their economic prospects, and be more informed and active citizens, no matter where in the world they live" (UIL, 2016c, p. 8).

Within the UNESCO framework, the importance of lifelong learning (LLL) as a humanistic, rights-based, holistic, and sector-wide approach to learning is widely recognized. As the Concept Note of UIL (2016a) states, this recognition is no longer confined to specific countries or regions but also informs global education plans. The UIL asserts that the 2030 Agenda for Sustainable Development and the Education 2030 Framework for Action "represent a significant step forward in positioning LLL as a main driver of health, economic growth, employment, sustainable consumption and production, and environmental awareness." While LLL has an important role to 
play in achieving all the Sustainable Development Goals (SDGs), it is at the center of SDG Goal 4, which aims to ensure inclusive and equitable quality education and to promote LLL opportunities for all.

The achievement of the SDGs can be seen as both a great achievement within the global community and "too little too late," depending on your perspective. They carry within them hope and skepticism- -"hope" because at last sustainable development is agreed on as the most critical frame for the United Nations to reference as it tackles global issues and "skepticism" because in the views of some analysts like Jason Hickel (2015), "The SDGs fail us .... They offer to tinker with the global economic system in a well-meaning bid to make it all seem a bit less violent. But this is not a time for tinkering."

Another contemporary document relevant to this discussion as a scene setter, which also comes from the UNESCO (2015), is Rethinking Education: Towards a Global Common Good? This is a contribution to re-visioning education in a changing world and builds on UNESCO's main task as a global observatory of social transformation. Its purpose is to stimulate public policy debate focused specifically on education for a rapidly changing world. The book adopts two central categories: a humanistic vision of education and education as a common good, beyond the notion of public good. Rosa Maria Torres (2016) believes that both concepts may be of help to rethink ALE within new social realities such as increased life expectancy of the population worldwide and the LLL paradigm. However, she states that ALE is largely absent in the document and "has a marginal place in Goal 4 of the SDGs." This may seem odd given that all the initiatives are within UNESCO's ambit.

Drawing from these three "contextual moments," the GRALE III report, therefore, is imbedded within competing worldviews where it is recognized by some as "a main driver of health, economic growth, employment, sustainable consumption and production, and environmental awareness" (UIL, 2016b) — essential as a counterforce to fake news or post-truth and, simultaneously, barely recognized within the spheres of formal educational discussion and provision.

\section{Background to the GRALE III Report}

Roughly every 12 years starting in 1949, UNESCO has convened an International Conference on Adult Education (Confintea) - in 2009 it was Confintea VI. At these conferences, members of UNESCO commit to the achievement of particular goals for the next 12 years. The first GRALE report was compiled in 2009 and was based on detailed country reports submitted by 154 countries. This was the first undertaking of a global report on the status of ALE. GRALE II was completed in 2013 and was based on data collected from 141 countries.

As key to the midterm Confintea review, GRALE III was produced with an editorial team, working with researchers, with UIL staff coordinating and finalizing the report. This third report was guided by three goals: first, to analyze the results of a monitoring survey of UNESCO member states and to take stock of whether countries are fulfilling the commitments they made at Confintea VI through the Belem Framework for Action; 
second, to strengthen the case for ALE with evidence of the benefits on health and wellbeing, employment and the labor market, and social, civic, and community life; and third, to provide a platform for debate and action at national, regional, and global levels.

As part of the process of gathering data for GRALE, UNESCO invited 197 countries to complete a monitoring survey consisting of 75 questions that included a mix of multiple-choice and open-ended questions. Completing all questions was not compulsory, and many of the 139 countries that submitted the surveys included unanswered questions. Thus, GRALE encouraged countries to undertake a self-assessment exercise and to consider their progress in each of the five action areas identified in the Belem Framework for Action. GRALE III reflected the move toward a more holistic view of education and LLL embedded in the 2030 Agenda for Sustainable Development. This holistic view is the rationale behind the three key frames that were used for the report: health and well-being, employment and labor market, and social, civic, and community life. This move is also reflected in the staff of UIL drawing in external partners for the survey - these included the World Health Organization, the International Labour Organization, and the Organisation for Economic Co-operation and Development, as well as academic experts in the field of ALE. Bringing these partners in ensured that existing data sources, such as the UNESCO Institute for Statistics data were drawn on to devise the 75 questions covering the five areas of action: policy; governance; financing; participation, inclusion, and equity; and quality.

As mentioned above, the survey was completed by 139 of the 197 member countries. Most of the countries that participated in GRALE I and GRALE II also participated in GRALE III, with the notable exception of the United Kingdom and Botswana. Both these countries have long histories of participating in ALE, and it would be useful to know why they did not participate in the survey.

\section{Discussion of Findings of GRALE III}

It is our intention here not to regurgitate the findings of the report but to highlight certain ones that are illustrative of the conundrum the authors of the report faced and that face ALE advocates, policymakers, practitioners, and scholars alike.

The key headline messages that the authors synthesize from the report are as follows:

1. Countries report progress in all areas of the 2009 Belem Framework of Action.

2. ALE is a key component of LLL and will make a major contribution to the 2030 agenda for sustainable development.

3. Levels of literacy among adults remain alarmingly low.

4. Gender inequality continues to be a concern.

5. Despite notable progress in monitoring and evaluation since 2009, basic data on ALE continue to be inadequate, and thus, the true effects of ALE are poorly understood.

6. Looking ahead to 2030-how can ALE equip people to meet the demands of the future? 
The following definition of ALE was provided in the GRALE III monitoring survey:

ALE encompasses all formal, non-formal and informal or incidental learning and continuing education (both general and vocational, and both theoretical and practical) undertaken by adults (as this term is defined in any one country). ALE participants will typically have concluded their initial education and training and then returned to some form of learning. But in all countries there will be young people and adults who did not have the opportunity to enrol in or complete school education by the age foreseen, and who participate in ALE programmes, including those to equip them with literacy and basic skills or as a "second chance" to gain recognized certificates. (UIL, 2016b, p. 29)

One of the questions posed in the survey was whether the definition that they use for ALE has changed since 2009 . Of the 118 countries that answered this, $62 \%$ responded that it had not changed, $25 \%$ responded that it had changed a little, and $13 \%$ responded that it had changed substantially. The report found that definitions of ALE vary widely depending on the immediate needs, priorities, and contexts of their populations. Some countries position literacy as a core focus of their ALE activities, while others see it more broadly. It would be interesting to find out why people responded as they did and what they meant.

The question of definition is obviously a key one and has major implications for any attempts to monitor "a moving target." It also has major implications for who was asked to fill in the survey when it arrived in a particular country and the responses flow from there. An example of this in the South African context is captured in an article (Walters, 2006) titled "Adult Learning Within Lifelong Learning: A Different Lens a Different Light." If analysts use adult basic education as the lens, the analysis of achievements of ALE will be very different than if a wider, more inclusive lens is used. When viewing the South African survey submission, it conveys the narrow adult basic education conception of ALE and does not include the fact that a new Department of Higher Education and Training has been established in which workplace skills training is included. As we have both been involved for many years in adult education in South Africa, and have in the past been authors of the South African country submission to UIL, we find this particularly concerning.

Recognizing this disparate understanding of ALE is important in determining how far countries have come in achieving the Belem Framework of Action goal of an investment of $6 \%$ of GNP in education including an increasing allocation to ALE. The GRALE III reports progress toward achieving this target as well as an increase in the ability of countries to provide such information. However, irrespective of whether countries have used a broad definition of ALE or a narrow one, the actual spending as a proportion of GDP remains depressingly low as $42 \%$ of countries reported spending less than $1 \%$ of GDP on ALE. The report acknowledged that spending on ALE by the private sector was difficult to assess and has probably been excluded in these estimates.

The exception is Finland who reported spending 10\% of GDP on ALE. Comparing the impact and type of ALE provided to the citizens of Finland with a country such as the United States who reported spending between $0 \%$ and $0.4 \%$ of GDP could be of value. 
Some insight on how broadly different countries perceive ALE and therefore include in their assessment of the budget of ALE can be better achieved by looking at what countries selected as their target populations. Under the section on policy, countries were asked to select a maximum of 5 target groups from a list of 16. Predictably, the most commonly selected target group at $81 \%$ was adults with low-level literacy or basic skills, indicating that ALE is still primarily seen as a "literacy" or adult basic education activity. The second most selected group at 59\% was young people not in education, employment, or training, the so-called NEETS, indicating how widespread this group is across the globe. On a positive note, in terms of the broader understanding of ALE as a holistic activity was the selection by more than $40 \%$ of countries of individuals seeking personal growth and widening of knowledge horizons and individuals seeking to update workrelevant knowledge and skills. However, target groups such as migrants, refugees, people living with disabilities, and senior citizens were all selected by less than $20 \%$ of countries despite being recognized as growing populations in many countries.

Developing better understandings of how and why countries select certain target groups and ignore others could assist in detecting possible barriers to socioeconomic transformation. GRALE III records that $71 \%$ of countries reported accrediting, validating, and recognizing nonformal and informal learning. Again, it is impossible to determine what each country includes and excludes in these forms of learning. Developing a better understanding of the impact of nonformal and informal learning is similarly complicated.

As researchers, we recognize that deciding on what to include or exclude in such a survey provides numerous challenges. Developers of this survey had to create a balance between asking too much and running the risk of respondents losing interest and making it too short so that only broad-stroke basic data are gathered that are useless. We feel that the survey has achieved this balance to some degree, but inevitably we wish there was more. In reading the report, we wanted answers to questions that the data raised. For example, we appreciated that recognizing the education of the adult educators was an important indicator of quality but wished that there were also some data collected on the actual uptake by such educators on the in-service training provided, and also what type of support was found to be most useful by them.

Also, in numerous sections of the report, one geographic area was very different from the other areas, and it was difficult to determine the reasons. One such example was that almost $70 \%$ of the Arab States were reported as having a policy framework to recognize nonformal and informal learning before 2009. This is considerably higher than all other areas; the world average was $40 \%$. What could the reason for this be?

In the section on health and well-being, we noted that illiteracy was reported by 90 countries as an important factor preventing ALE from having an impact on health and well-being. How is this understood? Are they working around the "illiteracy" with the use, for example, of voice recordings with mobile technology? The second highest factor preventing ALE, reported by 64 countries, was "inadequate or misdirected funding." Unfortunately the question did not distinguish between the common problem of "inadequate funding" and the more problematic "misdirected funding"- the meaning of the latter concept is not elaborated. 
In general terms, the data presented are likely to raise more questions than they answer. They are rarely able to capture informal or nonformal learning, which is where a large proportion of ALE takes place.

\section{Reflections on the GRALE III Report}

Our general observation is that this is a visionary document, which is articulated through the bringing together of data from a range of areas that are usually kept apart. These are adult literacy and basic education, health, employment and labor market, and social, civic, and community life. It is a bold attempt to project what role ALE plays, or could play, within a holistic philosophy and approach to LLL. It attempts to thread together in interlinked ways worlds that are so often kept apart through the structures of financing and governance of ALE. It is an important advocacy document toward a collective conceptual understanding and approach to a humanistic, rights-based, holistic, and sector-wide approach to ALE. This is necessary for achievement of the SDGs.

The document is simultaneously addressing a range of audiences both inside and outside the world of ALE itself. It is speaking to global, regional, and national policymakers, politicians, ALE advocates, and education and training leadership and practitioners. It is both advocating for and opening up debates in search for understanding of complex and difficult dilemmas in politically fraught terrain. It is attempting to remake a "social contract" in the environment of ALE in a "fierce new world" (Sen \& Durano, 2014). This is a very complex and ambitious undertaking. We use the term social contract as used by Sen and Durano (2014), which is imbedded in the political economy of power and inequality at multiple levels and in varied forms. As they say, it is "a collective agreement that is built on and imbued with power" (p. 5). We would agree that social contracts are always in a state of flux, so they require constant pedagogical and political work. Working at the global level is extremely complex. As Phillip de Wet (2017) says in the context of President Trump's recent actions, "Analysts agree that getting things done on the international stage takes nuance and skill, deft handling, careful consensus-building and a minimum of strong arming." By inviting member states to self-report, GRALE III adopts a necessary "light touch."

The downside, however, is that the data received require interrogation if they are to stand up to scrutiny and deepen understanding of what is meant and why. We would suggest that the next phase could be to interrogate a sample of particular countries' responses in order to develop a more robust understanding of ALE.

This then raises the question about the nature of this document - using Burawoy (2011) — does it mainly reflect instrumental or reflexive knowledge? Instrumental types of knowledge allow certain tasks to be accomplished, like policy-related ends or professional practice. Reflexive types of knowledge are directed more to scholarly communities concerned with critical knowledge. In terms of the purposes of the document, it seems to be attempting to achieve both. However, given the definitional problems and the unevenness of the data sources, it struggles to present a robust picture of what is occurring in ALE around the world. 
It could be that in presenting the report the distinctions between the two types of knowledge, which reflect the competing purposes of the report, are more clearly spelt out. If the report is seen in these terms, as part of a political and pedagogical intervention, then it may be easier to accept for practitioners, like those in Ougoudougou, who responded with disquiet to the dissonance between what the report conveys and their own lived realities. It is those adult educators who need to be mobilized to utilize the report to advocate for a more holistic vision for ALE within their own countries and regions if a new "social contract" for ALE is to be achieved.

\section{ALE in the Post-Truth Society?}

The dangers of the global trends toward populist authoritarianism for ALE are real. As a community of practitioners who are concerned with deepening possibilities for socially just, environmentally sustainable, and democratic societies, we look to the past as we confront the "fierce new world."

First, we suggest that the time has come for popular education to regain its position as critical to ALE. A new book, Forging Solidarity: Popular Education at Work (von Kotze \& Walters, 2017), argues that in the face of increased separation of people from one another and fear of "the other," we need to forge solidarity in order to counter the populist authoritarian turn. The authors quote well-known Brazilian political educator and activist Paulo Freire, who insisted,

Reality can be transformed and must be transformed. The fact is that my dreams remain alive; the power of my dreams leads me to say ... please do not give up. Do not allow this new ideology of fatalism to kill your need to dream. Without dreams there is no life, without dreams there is no human existence, without dreams there are no more human beings. (Freire, 2014, p. 33)

Popular education is a medium for dreaming, for imagining other futures. It takes place mainly in social movements and other civil society organizations where people join together to effect change. It is an unashamedly political process for decolonized human development, mobilization, and building community in the interests of the majority world. Forging solidarity is one of the means toward that end and, indeed, an end in itself.

Popular adult education is widespread in many countries as people struggle for sustainable livelihoods, peaceful coexistence, meaningful work, decent housing, or renewable energies. It is a critically important part of ALE, but because it is often informal and nonformal, and is integrated into community organizing, it is largely invisible within GRALE III. The traditions of popular education need once more to be recognized as integral to ALE and building a sustainable planet.

As part of this, we suggest a return to social and political theory and to theorists like Hannah Arendt, Antonio Gramsci, Franz Fanon, or Steve Biko who have studied the rise of totalitarianism in different forms, whether in Germany, Italy, Algeria, or South Africa. They, and many others, can assist collective understandings of what may be happening today and how to resist and shape alternative futures. 
Moving from the macro- to the micro-pedagogical interventions, commentators and educators are stressing the importance of various forms of literacy to be able to "read the world"- that is, check fake news - which can have real-life consequences. We need to learn to become "fact checkers" to decode the fake from the real facts. For educators, these strategies are not new as any academic literacy course at school or college will confirm. However, the emphasis is now on learning to "read" and "interpret" social media that we encounter every day in far greater volumes. We need to engage in agnotology - that is, the study of deliberate propagation of ignorance - so that we limit our complicity in antidemocratic practices.

The stakes are high for the survival of the planet. ALE has a critical role to play. The political and pedagogical work undertaken by GRALE III is at an early stage. These efforts need our collective and individual support as scholar-activists, policymakers, practitioners, and advocates to ensure that these actions become ever more useful and effective.

\section{Declaration of Conflicting Interests}

The author(s) declared no potential conflicts of interest with respect to the research, authorship, and/or publication of this article.

\section{Funding}

The author(s) received no financial support for the research, authorship, and/or publication of this article.

\section{References}

Burawoy, M. (2011). Redefining the public university: Global and national contexts. In J. Holmwood (Ed), A manifesto for the public university (pp. 27-41). London, England: Bloomsbury.

de Wet, P. (2017, February 10). Dark days ahead if you're hoping for change. Mail \& Guardian, p. 6. Retrieved from https://mg.co.za/article/2017-02-10-00-dark-days-ahead-if-yourehoping-for-change

Freire, P. (2014). Pedagogy of solidarity. In P. Freire, A. M. Araujo Freire, \& W. de Oliveira (Eds.), Pedagogy of solidarity (pp. 15-34). Walnut Creek, CA: Left Coast Press.

Harris, S. A. (2016, November). Post-truth chosen as Oxford Dictionaries word of the year 2016. Retrieved from http://www.huffingtonpost.co.uk/entry/post-truth-oxforddictionaries-word-of-the-year-2016_uk_582c0ecae4b0311a3da227c8. Accessed April $3,2017$.

Hickel, J. (2015, August 8). The problem with saving the world: The UN's new Sustainable Development Goals aim to save the world without transforming it. Jacobin. Retrieved from https://www.jacobinmag.com/2015/08/global-poverty-climate-change-sdgs/

Kenyon, G. (2016, January 6). The man who studies the spread of ignorance. Retrieved from http://www.bbc.com/future/story/20160105-the-man-who-studies-the-spread-ofignorance?ocid=ww.social.link.email.

Sen, G., \& Durano, M. (2014). The remaking of social contracts: Feminists in a fierce new world. London, England: Zed Books. 
Torres, R. M. (2016, April). Response to Rethinking Education. Comments at the Regional Consultation with Civil Society on the document Rethinking Education: Towards a Global Common Good? Brasilia, Brazil.

UNESCO. (2015). Rethinking education: Towards a global common good? Paris, France: Author.

UNESCO Institute for Lifelong Learning. (2016a). Concept note: Third think tank meeting on lifelong learning. Hamburg, Germany: Author. Retrieved fromhttp://www.uil.unesco.org/ event/think-tank-meeting-lifelong-learning-2030-agenda-sustainable-development

UNESCO Institute for Lifelong Learning. (2016b). 3rd Global Report on Adult Learning and Education III. Hamburg, Germany: Author. Retrieved from http://uil.unesco.org/system/ files/grale-3.pdf

UNESCO Institute for Lifelong Learning. (2016c). 3rd Global Report on Adult Learning and Education III: Key messages and executive summary. Hamburg, Germany: Author. Retrieved from http://uil.unesco.org/system/files/grale-3-executive-summary.pdf

von Kotze, A., \& Walters, S. (Eds.). (2017). Forging solidarity: Popular education at work. Rotterdam, Netherlands: Sense.

Walters, S. (2006). Adult learning within lifelong learning: A different lens, a different light. Journal of Education, 39, 7-26.

\section{Author Biographies}

Shirley Walters has been professor of adult and continuing education at the University of Western Cape for 30 years. She is active in national and international adult education movements and is currently deputy president for Africa for the International Council for Adult Education.

Kathy Watters is a research associate of the University of Western Cape and has been active as both practitioner and researcher in the field of adult education over the last 30 years. 